\title{
The Magnitude and Associated Factors of Consistent Condom Utilization Among ART Users in Hawassa City, Sidama, Ethiopia
}

This article was published in the following Dove Press journal: HIVIAIDS - Research and Palliative Care

\author{
Biruk Tesfaye' \\ Yohannes Seifu (iD ${ }^{2}$ \\ Bereket Tekleselassie ${ }^{2}$ \\ Amanuel Ejeso ${ }^{3}$ \\ 'School of Public Health, Yirgalem \\ Medical College, Hawassa University, \\ Hawassa, Ethiopia; ${ }^{2}$ School of Public \\ Health, College of Medicine and Health \\ Sciences, Hawassa University, Hawassa, \\ Ethiopia; ${ }^{3}$ Department of Environmental \\ Health, College of Medicine and Health \\ Sciences, Hawassa University, Hawassa, \\ Ethiopia
}

Background: Antiretroviral therapy (ART) introduction has sharply decreased mortality and morbidity rates among HIV-infected patients and resulted in longer and healthier lives among people living with HIV. Hence, the aim of this study is to determine the level of consistent condom use and associated factors among ART users in Hawassa City.

Methods: Cross-sectional study design triangulated with qualitative phenomenology was used. One hospital and one health center were selected by simple random sampling and proportional to size allocation was used to assign participants to each health facility. Accordingly, 358 study subjects were selected. Adjusted odds ratio (AOR) with 95\% confidence interval was used to implicate significant factors. Thematic content analysis was used and narrative report writing with a quote was used to present qualitative data.

Results: The prevalence of consistent condom utilization in this study was $51.4 \%$. Sex $(\mathrm{AOR}=4.20,95 \% \mathrm{CI}: 2.386,7.41)$, residence $(\mathrm{AOR}=3.55,95 \% \mathrm{CI}: 1.81,6.99)$ educational status $(\mathrm{AOR}=0.4,95 \% \mathrm{CI}: 0.196,0.946)$, perception on ART's does not reduction of HIV transmission $(\mathrm{AOR}=1.96,95 \% \mathrm{CI}: 1.12,3.43)$, rate of counseling ( $\mathrm{AOR}=0.37,95 \% \mathrm{CI}: 0.17$, 0.84 ) and use condom to prevent pregnancy ( $\mathrm{AOR}=4.53,95 \% \mathrm{CI}: 2.11,9.73$ ) were found to be independent predictors of consistent condom utilization among ART users. Refusal by husbands, decrement in satisfaction, gender difference with more women than men willing to use consistently and religious reasons were factors associated with inconsistent condom utilization in the qualitative study.

Conclusion and Recommendation: Consistent condom utilization among ART users was low. Sex, residence, educational status, perception towards ART were significantly associated with consistent condom utilization. Moreover, husband refusal, religious reason, decrement in satisfaction on the qualitative study were associated with non-consistent use of a condom. The importance of consistent condom use should be well addressed in HIV/AIDS patients, to prevent transmission and multiple infections of HIV.

Keywords: condom utilization, HIV/AIDS, Hawassa City

\section{Introduction}

Since the beginning of the epidemic, around 71 million people have been infected with the HIV virus and about 34 million people have died of HIV. According to UNAIDS. There were approximately 37.9 million people across the globe with HIV/AIDS in 2018. Of these, 36.2 million were adults and 1.7 million were children ( $<15$ years old). ${ }^{1}$ According to the joint United Nations program on HIV/AIDS, 35.3 (32.2-38.8) million people were living with HIV in 2012 worldwide, with 2.7 million being newly infected. The number of AIDS-related deaths is $1.6(1.4-1.9)$ million in $2012 .^{2}$
Correspondence: Yohannes Seifu Department of Biology, College of Natural and Computational Science, Hawassa University, Hawassa 005, Ethiopia

Email johnseifu80@gmail.com 
Unprotected sexual intercourse with an HIV-infected person easily transmits infection and will increase the disease incidence and prevalence. Transmission of HIV and STDs can occur with a single sex act with an infected partner due to inconsistent or nonuse of condoms and Individuals with multiple sexual partners without using a condom increases the risk of contracting HIV. Population groups including commercial sex workers, people who inject drugs, transgender people, prisoners, and gay men and other men who have sex with men have higher risk of HIV infection. ${ }^{3,4}$

Consistent condom use among HIV/AIDS patients is vital to prevent the transmission of the virus and to prevent other multiple infections in already infected persons. ${ }^{5}$ Factors considered as barriers to the consistent use of condoms with stable partners include the belief that condoms are of no importance in an HIV positive seroconcordant relationship, poor sexual satisfaction with condoms, the need to raise a child, use of alcohol by the husband, anxiety, depression, inadequate counseling by healthcare providers. $^{2,3}$ The correct and consistent use of condoms decreases the risk of transmission of HIV from very low to negligible. ${ }^{2,3}$

Condoms are an important weapon in the battle against HIV/AIDS, sexually transmitted infections as well as unwanted pregnancies. ${ }^{6}$ Condom use is a critical component in a comprehensive and sustainable approach to the prevention of HIV and other sexually transmitted infections (STIs) and for preventing unintended pregnancies especially among people with HIV positive clients. ${ }^{7}$ The maximum protective effect of condoms is achieved when their use is consistent rather than occasional. ${ }^{8}$ Condoms act as a barrier in preventing body fluids containing HIV from coming into contact with parts of the body vulnerable to HIV infection. ${ }^{9}$ There are two main types of condom: the external (male) and the internal (female) condoms. The external condom is placed on erect penis and the internal condom is placed within the vagina or rectum. Condom is the only HIV prevention strategy that can also reduce the risk of sexually transmitted infections (STI) and pregnancy. ${ }^{10}$

Ethiopia is among the countries most affected by the epidemic. With an estimated adult prevalence of $1.5 \%$, and have a large number of PLWHA approximating 800,000, and about 1 million AIDS orphans. ${ }^{11,12}$ The most common mode of HIV transmission is heterosexual which accounts for $87 \%$ of infections. Another $10 \%$ of infections occur due to mother to child transmission (MTCT) ${ }^{13}$ In Ethiopia a total of 333,434 people had ever started ART. There were 249,174 adults ( $86 \%$ of eligible) and 16,000 children currently on treatment ( $20 \%$ of eligible) by the end of 2011.

The launching of ART was a prevention policy in reducing mortality and improving the quality of life of PLWHA. Today, ART has become a vital part of HIV related mortality reduction and care. ${ }^{13}$ And due to the success of highly active antiretroviral therapy (HAART), morbidity and mortality from HIV disease is noticeably diminishing, many HIVinfected persons are now living longer, healthier, and more sexually active lives. ${ }^{14}$ Yet, there is evidence that engaging in unprotected sex with HIV positive individuals is high-risk sexual behavior for HIV transmission on Sero-discordant partners and re-infecting themselves with new, drugresistant strains of the virus. ${ }^{15-18}$ Several studies have shown that access to ART has not led to significant risky sexual behavior among HIV-infected persons. The studies of the developed world suggested that individuals who are HIVinfected tend to decrease their sexual risk behavior after the initiation of ART. The finding of other studies conducted in developing countries showed that access to ART has not led to significant risky sexual behavior. ${ }^{19,20}$ Nevertheless, PLWHA is still engaging in unprotected intercourse, and hence at the potential risk for HIV transmission.

On the other hand, some concerns providing ART may lead to an increase in sexual risk behaviors because of the improved quality of life associated with $\mathrm{ART}^{21}$ As the health of people living with HIV improves due to continual use of ART, many resume sexual activity from a study done in rural Uganda. ${ }^{22}$

Previously, the focus of HIV prevention efforts in most countries including Ethiopia was largely on people uninfected with HIV. Sexual risk practice of HIV-infected persons did not receive due attention. Inconsistent use/ nonuse of condom by PLWHA on ART will lead to further worsening the HIV infection epidemic and reinfection with new drug-resistant viral strains. The emphasis has been on people uninfected with HIV. As a result, data regarding the magnitude of consistent condom use among HIV/AIDS patients appear to be scarce. Therefore, the aim of this study is to determine the level of consistent condom use and associated factors among ART Users in Hawassa city.

\section{Methods}

\section{Study Setting}

The study was conducted among ART attendees in health facilities at Hawassa city administration; Sidama Region 
which is located $275 \mathrm{~km}$ south of Addis Ababa. The total population is estimated to be 351,567 comprising $48.5 \%$ $(170,510)$ females and $51.5 \%(181,057)$ males. The city is composed of 8 sub-cities. It has 21 urban and 11 rural kebeles. Currently, the city has 2 public hospitals and 10 health centers. There are five health facilities, two hospitals, and three health centers providing ART chronic care services in the city. According to the City health department, until October 2019, the number of PLWHA on ART was 4636.

\section{Study Design, Period and Sample Size}

Mixed design including both qualitative and quantitative approach has been employed. Under quantitative, institution-based cross-sectional and qualitative phenomenology design was used. The study was conducted from January 2019 to March 2019.

The sample size was calculated for the first specific objective by using the Stat calc program of Epi info by considering $50.2 \%$ consistent condom use in study conducted in Northwest Ethiopia, 5\% margin of error, $Z$ scores corresponding to $95 \%$ confidence interval, and total 4636 source population giving 355 sample size.

The total sample size with a $10 \%$ rate of non-response was 391. The sample size is also calculated for second specific objectives by using EPI INFO, Statcalc program based on the finding from research done in northwest Ethiopia $^{23}$ (Table 1) Based on the above result, the sample size calculated for first specific objective (391) was greater than second specific objectives, so it was taken as the sample size for the study.

\section{Source Population}

The study populations are all people living with HIV/ AIDS who receive ART chronic care from health institutions found in Hawassa city administration.

\section{Study Population}

PLWHA who are on ART in selected health institutions of Hawassa City administration. For the qualitative part purposively selected PLWHA on ART were used. The selection was made by ART providers for they know study participants very well and health professionals working on ART clinics for at least 6 months were selected.

\section{Inclusion and Exclusion Criteria Inclusion Criteria}

ART attendees in the age group 18-49 years who have been practicing sexual activities, using a condom, for the last 3 months were included in the study.

\section{Exclusion Criteria}

Those who are seriously ill and unable to communicate verbally were excluded from the study.

\section{Sampling Technique}

\section{Quantitative Sampling Technique}

The study was conducted in health facilities providing ART services in Hawassa city. Two public hospitals and three health centers are currently providing ART services in the city. Out of them Adare hospital and Loke health center were selected by simple random sampling and the sample has been allocated proportionally. A systematic random sampling technique was used every 5th clients coming for the service was interviewed and when the selected clients did not satisfy the inclusion criteria the next clients were included in the study.

\section{Qualitative Sampling Technique}

Purposive sampling method has been used to select PLWHA on ART \& ART care providers and counselors. Data were collected till saturation of idea and this has happened with 12 PLWHA and 3 ART care providers.

\section{Data Collection Tool and Procedures Quantitative Data Collection Procedures}

Pre-tested structured questionnaires that were adopted with some modification from related studies and Ethiopian demographic health ${ }^{12,24,36}$ survey were used. The questionnaires were translated from English to Amharic \& back to English. The data were collected by 4 ART providers and caregivers (two from each institution)

Table I Sample Size for Second Specific Objectives, 2019

\begin{tabular}{|l|l|l|l|l|l|l|l|l|l|}
\hline No & Variables & $\begin{array}{l}\text { Level of } \\
\text { Confidence }\end{array}$ & Power & $\begin{array}{l}\% \\
\text { Unexposed }\end{array}$ & Ratio & $\begin{array}{l}\% \\
\text { Exposed }\end{array}$ & $\begin{array}{l}\text { OR } \\
\text { Response }\end{array}$ & $\begin{array}{l}\text { Total } \\
\text { Sample }\end{array}$ \\
\hline $\mathbf{I}$ & Age( $\geq 32)$ & $95 \%$ & $80 \%$ & 45 & $1: 1$ & 62.1 & 2 & $10 \%$ & 319 \\
$\mathbf{2}$ & Educational status & $95 \%$ & $80 \%$ & 59 & $1: 1$ & 84.6 & 3.81 & $10 \%$ & 327 \\
$\mathbf{3}$ & Use of substance(yes) & $95 \%$ & $80 \%$ & $33 \%$ & $1: 1$ & 49.6 & 2 & $10 \%$ & 121 \\
\hline
\end{tabular}


supervised by a health professional holding a BSc degree and the principal investigator as well. The Interviews have taken place in strictly private rooms prepared near to ART clinics.

\section{Qualitative Data Collection Procedures}

Phenomenology design was used and an in-depth interview was conducted among selected participants. The data were collected by the principal investigator with two assistant data collectors. The interview was facilitated by using interview guiding questions. All the interviews were tape-recorded and additional notes were taken during the scenes. The principal investigator with the data collectors transcribed the taperecorded data after each session and finally, the transcripts were translated into English for analysis.

\section{Quality Assurance Techniques Quantitative Data Quality Assurance}

The data collectors and supervisors were trained by the principal investigator for a day on the detailed procedures of the task before the data collection. Questionnaires were translated from English to Amharic and back to English to verify its consistency. Before the actual data collection, a pretest was done on $5 \%$ of the same source population at Millennium \& Tula health centers to assess the clarity of tools, length of duration on collection, completeness, and skip patterns. Then, extra briefing was given to the data collectors and supervisor. There also was daily scrutiny for completeness and consistency of the questionnaires with feedbacks to the collectors.

\section{Qualitative Data Quality Control}

The quality was maintained through training of data collectors on the collection procedure, recording, and notetaking. Quit \& comfortable places were selected for data collection to allow maximum concentration and interest on the topic. Participants were requested to give an ingenious answer by explaining the purpose and importance of the study and assuring the confidentiality of the information they were about to provide.

\section{Dependent and Independent Variable}

Dependent variable was Consistent condom utilization (use of condom in every sexual encounter in the last 3 months preceding the study) and Independent variables included Socio-demographic characteristics such as sex, age, residence, religion, level of education, occupation, income, and marital status. ART and related factors such as duration with HIV diagnosis, duration of ART, perception towards ART, condom use before testing positive for HIV, condom use before ART and current CD4. Behavioral factors such as risky sexual behavior, knowledge of partner HIV status, disclosure of HIV status, knowledge on importance of condom, discussion about condom use and alcohol. Service related such as counseling.

\section{Operational Definitions Consistent Condom Use}

Consistent condom utilization was measured by asking how many times the participant had vaginal sex with each named partner in the past 3 months and then asking in how many of these sexual encounters were a condom used. It was defined as using a condom at every reported sexual encounter in the past 3 months with that partner.

\section{Unprotected Sex}

Sex without a Condom in the last 3 months.

\section{Regular Partners}

Husband/wife with whom one has a continual sexual relationship.

\section{Commercial Sex Workers}

Clients paid for sex.

\section{Casual Partners}

Sexual partner with whom one has not met before having sex.

\section{Data Management and Analysis}

Data were coded and cleaned by running frequency and cross-tabulation after it was exported from Epi Info version 3.5.1 to SPSS version 24 windows. Descriptive statistics, bivariate logistic regression analysis was done to select potential candidate covariates and variables with P-value $<0.25$ were candidate variables for multi variable analysis. Multivariable logistic regression has been computed. The backward model building method was used while building the model.

After checking for fitness of the logistic regression model (Hosmer \& Lemeshow), the results of the final model were expressed in terms of adjusted odds ratio (AOR) and 95\% confidence intervals (CI), and Statistical significance was declared when the P-value was less than 0.05 . The qualitative data have been analyzed using open code. First, the audiotaped data were transcribed and 
translated into English by the principal investigator, and then translated data have been imported to open code to facilitate coding. Based on key concepts some codes were developed. After coding, categories were developed showing the clear meaning of the findings and the single theme represented overall combined interpretation of the qualitative data and quantitative information was given. Finally, the results of the qualitative studies were presented with the results of the quantitative study.

\section{Result}

\section{Socio Demographic and Economic Characteristics of PLWHA Who are on ART}

A total of 358 clients on ART were included in the study with a response rate of $92 \%$. The majority of respondents 248 (69.3\%) were from the ART clinic of Adare Hospital. Most of the respondents 208 (58.1\%) were female, the mean age of participants was $32.9( \pm 6.6 \mathrm{SD})$ years and the majority $(52.2 \%)$ were between the age of 25-34 years. One hundred thirty-two $(36.9 \%)$ of the participants had attained primary education and $200(55.9 \%)$ of them belong to the orthodox religion group followed by protestants. More than two-thirds $(69.6 \%)$ of the participants reside in an urban area and less than one third $(23 \%)$ of them were housewives. Seventy four percent (265) of participants reported that they were married (Table 2).

\section{HIVIAIDS and ART-Related Characteristics}

Two hundred forty-eight (69.3\%) were aware of their HIV positive status for more than 2 years and $195(54.5 \%)$ of the respondents have been on ART for the same duration. More than half $(53.9 \%)$ do not perceive ART reduce HIV transmission, another $46.1 \%$ perceive that ART reduce the chance of transmission and this was supported by a qualitative study in which the key informant from health center said,

There are many others who do not use a condom even being discordant thinking that there would be no transmission as long as they are on ART though we try to falsify their beliefs through counseling that the ART would not stop transmission $\&$ re-infection. here is the story of a young beautiful lady who is a teacher by profession, there is a guy that works in Hawassa referral hospital who usually nags her to make love (have sex) with him but she told him that she was HIV positive \& he didn't trust her, it kept this way for a long time $\&$ he still failed to understand her. she finally told him that she would contact
Table 2 Distribution of Socio Demographic and Economic Characteristics of PLWHA Who are on ART in Health Facilities Found in Hawassa City Administration, $2019(n=358)$

\begin{tabular}{|c|c|c|c|}
\hline Variables & Response & Frequency & $\%$ \\
\hline \multirow[t]{2}{*}{ Facility } & Hospital & 248 & 69.3 \\
\hline & Health Center & 110 & 30.7 \\
\hline \multirow[t]{2}{*}{ Sex } & Male & 150 & 41.9 \\
\hline & Female & 208 & 58.1 \\
\hline \multirow[t]{4}{*}{ Age } & $18-24$ & 27 & 7.5 \\
\hline & $25-34$ & 188 & 52.2 \\
\hline & $35-44$ & 120 & 33.5 \\
\hline & $\geq 45$ & 23 & 6.4 \\
\hline \multirow[t]{4}{*}{ Educational status } & No education & 56 & 15.6 \\
\hline & Primary & 132 & 36.9 \\
\hline & Secondary & 114 & 31.8 \\
\hline & Above secondary & 56 & 15.6 \\
\hline \multirow[t]{4}{*}{ Religion } & Orthodox & 200 & 55.9 \\
\hline & Muslim & 27 & 7.5 \\
\hline & Protestant & 112 & 31.3 \\
\hline & Catholic & 19 & 5.3 \\
\hline \multirow[t]{2}{*}{ Residence } & Urban & 249 & 69.6 \\
\hline & Rural & 109 & 30.4 \\
\hline \multirow[t]{6}{*}{ Occupation } & Gover. employee & 82 & 22.9 \\
\hline & Private employee & 66 & 18.4 \\
\hline & Housewife & 83 & 23.2 \\
\hline & Daily laborer & 34 & 9.5 \\
\hline & Merchant & 81 & 22.6 \\
\hline & Others & 12 & 3.4 \\
\hline \multirow[t]{5}{*}{ Marital status } & Never married & 48 & 13.4 \\
\hline & Married & 265 & 74 \\
\hline & Cohabiting & 11 & 3.1 \\
\hline & Divorced & 16 & 4.5 \\
\hline & Widowed & 18 & 5 \\
\hline Household & $\leq 600$ & 56 & 15.6 \\
\hline \multirow[t]{2}{*}{ Income } & $601-1000$ & 137 & 38.3 \\
\hline & $>1000$ & 165 & 46.1 \\
\hline
\end{tabular}

him with the person who offers her ART drugs when he fails to trust her \& this was his response 'as long as you are on ART, there would be no risk of transmission even if we make sex without a condom' \& she complains that she receives the same question from male ART clients (Table 3).

\section{Prevalence of Consistent Condom Utilization After ART}

Almost all 331 (92.5\%) respondents had sex with only one sexual partner in the past three months. Among these 
Table 3 Distribution of HIVIAIDS and ART-Related Characteristics of PLWHA Who are on ART in Hawassa City Administration, $2019(n=358)$

\begin{tabular}{|l|l|l|l|}
\hline Variables & Response & Frequency & $\%$ \\
\hline Duration since tested positive & $<12 \mathrm{~m}$ & 26 & 7.3 \\
& $12-24 \mathrm{~m}$ & 84 & 23.5 \\
& $\geq 25$ & 248 & 69.3 \\
\hline Duration on ART & $<12 \mathrm{~m}$ & 56 & 15.6 \\
& $12-24 \mathrm{~m}$ & 107 & 29.9 \\
& $\geq 25$ & 195 & 54.5 \\
\hline Perception that ART reduce & Yes & 165 & 46.1 \\
HIV transmission & No & 193 & 53.9 \\
\hline CD4 count of respondents & $\leq 500$ & 194 & 54.2 \\
& $>500$ & 164 & 45.8 \\
\hline Condom utilization before & Yes & 96 & 26.8 \\
knowing HIV status & No & 262 & 73.2 \\
\hline Frequent use of condom & Always & 2 & 2.08 \\
before status(n=96) & Most of the & 52 & 54.16 \\
& time & & \\
\hline Frequent use of condom & Occasionally & 37 & 38.54 \\
before ART(I8I) & Rarely & 3 & 3.125 \\
& Very rarely & 2 & 2.08 \\
\hline Condom utilization before & Yes & 181 & 50.6 \\
& No & 177 & 49.4 \\
\hline & time & 82 & 45.3 \\
& Occasionally & 36 & 32.04 \\
\hline & Rarely & 4 & 19.88 \\
& Very rarely & 1 & 2.21 \\
\hline & & 0.5 \\
\hline
\end{tabular}

participants, 269 (75.1\%) had sex with their regular spouse, those reported consistent condom uses were 184 (51.4) with the rest reporting inconsistent utilization (Figure 1).

More than half of 202 (56.4\%) condom user-initiated condoms by-themselves, in which most of the initiators were females. This was supported by a qualitative study, that one PLWHA woman interviewed from the hospital said ...

I start the conversation of condom use. He is not happy when I bring up the issue. Even though he is supposed to be careful as he is negative it's only my effort that drives us into using a condom, so I'm the one who starts the conversation

... Another woman said, ...

It is me who brings up the idea of condom use but he even never like to hear about HIV and when we make sex,

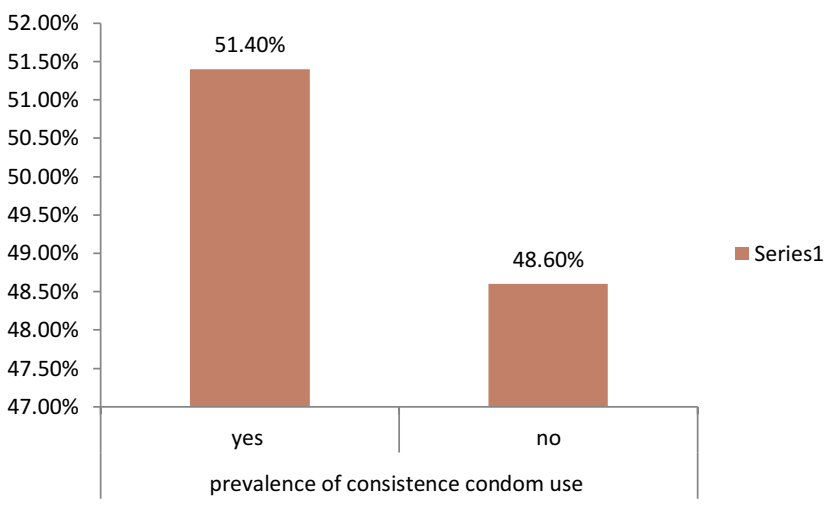

Figure I Prevalence of consistent condom utilization among PLWHA on ART at Hawassa City Administration, 2019.

I enforce him to put on condoms telling him that it feels pain without it though he complains lesser satisfaction

... Another married woman said, "It's me who initiates the idea of condom use. He usually says he's tired of it as an excuse but I am still trying with patience" ...

A man interviewed from the hospital said, "She (wife) is negative but both of us bring the issue. She asks me whether I'm wearing it or not \& even make sure with her hand if I am using it" ... Forty-four (12.3\%) of the respondents were drunk during their last sex and among them, $54 \%$ of alcohol consumers were both partners and the rest $45 \%$ was by partners of the respondents. Discussion on condom use and safe sexual practice carried out by $216(60.3 \%)$ of the respondents and more than $2 / 3$, $276(77.1 \%)$ of the respondents disclosed their status to their partners. $228(63.7 \%)$ participants reported that partners they had sex within the last 3 months are seropositive with $46(12.8 \%)$ being seronegative and the rest had unknown HIV status. Only 56 (15.6\%) of the respondents were members of the PLWHA association (Table 4).

\section{Perception on Benefits of Condom}

When it comes to perception on benefits of condom, 140 (39.1\%) of the respondents agreed that consistent use of condoms decreases the chance of reinfection by other strain of viruses Less than half of them 169 (47.2\%) strongly agreed that consistent condom utilization prevents partner transmission. More than half 200 (55.9\%) strongly agreed with the idea of consistent condom utilization preventing STI (Figure 2).

\section{Reason for Consistent Condom Use}

About 111 (31\%) of the respondents mentioned the reason for using a condom consistently as preventing pregnancy. 
Table 4 Frequency and Percentage Distribution of Sexual and Behavioral Characteristics and Condom Use of PLWHA Who are on ART in Hawassa City Administration, $2019(n=358)$

\begin{tabular}{|c|c|c|c|}
\hline Variables & Responses & Freq & $\%$ \\
\hline Number of sexual partners respondents & One & 331 & 92.5 \\
\hline had sex with In the past 3 months & Two & 27 & 7.5 \\
\hline \multirow{3}{*}{$\begin{array}{l}\text { Relation to respondents of partners } \\
\text { they had sex with }\end{array}$} & Regular spouse & 269 & 75.1 \\
\hline & Regular b/g friend & 47 & 13.1 \\
\hline & Casual contact & 32 & 11.7 \\
\hline \multirow{3}{*}{$\begin{array}{l}\text { Initiator of the idea of condom use } \\
\text { during sex }\end{array}$} & Respondent & 202 & 56.4 \\
\hline & Partner & 107 & 29.9 \\
\hline & Mutual decision & 49 & 13.7 \\
\hline \multirow{2}{*}{$\begin{array}{l}\text { Discussion with partners about condom } \\
\text { and safe sex }\end{array}$} & Yes & 216 & 60.3 \\
\hline & No & 142 & 39.7 \\
\hline \multirow[t]{3}{*}{ Knowledge of partner serostatus } & Negative & 46 & 12.8 \\
\hline & Positive & 228 & 63.7 \\
\hline & Do not know & 84 & 23.5 \\
\hline \multirow[t]{2}{*}{ Disclosure of self serostatus to partner } & Yes & 276 & 77.1 \\
\hline & No & 82 & 22.9 \\
\hline \multirow[t]{2}{*}{ Alcohol consumption during last sex } & Yes & 44 & 12.3 \\
\hline & No & 314 & 87.7 \\
\hline \multirow{2}{*}{$\begin{array}{l}\text { Consumer of alcohol during last sex } \\
(n=44)\end{array}$} & Partner & 20 & 45 \\
\hline & Both & 24 & 54 \\
\hline \multirow[t]{2}{*}{ Member in PLWHA association } & Yes & 56 & 15.6 \\
\hline & No & 302 & 84.4 \\
\hline
\end{tabular}

One hundred thirty (36.3\%) of them used to prevent STI \& $90(25.1 \%)$ to prevent reinfection by other strains of the virus (Figure 3).

\section{Reason for Non-Consistent Condom Use}

Partners' refusal (20.9\%) stood first among the reasons for inconsistent condom utilization and forty-one (11.5\%) of them said sex is not same with the condom, this finding has support from a qualitative study in which almost half of the respondents mentioned rejection by husbands and decreased satisfaction with condom, ART provider from the health center said,

Most of our clients are married couples \& some are from rural areas \& the main reason mentioned for nonconsistent use is a refusal by husbands, though we send women supplying condoms, they are obliged to throw it out by husbands at home. Some claims that they don't want to use for they both are positives.

Another provider from the same place said,
Most of the time husbands are not willing. Even if there are discordant results with husbands being negative there are some who prefer being infected to using a condom. There also comes complaints like minimal satisfaction when using condom \& dislike of its odor.

A provider form hospital said,

Their reasons are needing pregnancy by some, the second one is that when women are asked for their reasons of not using a condom, they mention rejection by husbands as a problem and when these husbands are asked, they reply that satisfaction is not the same like it is without a condom.

A man interviewed from the hospital said ...."I used to use it all the time but now after I'm put on HIV medications I only use it sometimes for it makes the satisfaction lesser" ... A woman from the same hospital said that ... "we use it most of the time but there are circumstances we do not use when my husband rejects" ... A husband from bigamous marriage who do not practice consistent condom with one of his wives said,

The reason I don't want to use with my second wife is that I want her to bear children very frequently. Even I would be glad if she could give birth twice a year(smile) because I want her beauty fade up to avoid others lusting after her looking at her beauty as she is young \& very beautiful.

Fourteen $(3.9 \%)$ of the participants mentioned unavailability of a condom and $1.4 \%$ of respondents reported desire of fertility, partner infection by HIV already, being under the influence of alcohol, not being aware that condom reduces re-infection, thought of partner being free from STI \& others respectively. Thirty $(8.4 \%)$ said they are already infected and a woman interviewed from health supported this saying,

Though they regularly offered me condoms, I never used it for almost a year after ART because I didn't see its importance as long as we both are positives but after then I suffered a lot from uterine infection and started using for the sake of the infection

$\ldots$ and $13(3.6 \%)$ feared asking partner to use a condom was supplemented by the idea of a man from the hospital who said, ...

She(his wife) told me that she was taught to use the condom in order to prevent pregnancy so I used to use it just to make her happy but now I don't use it when I don't feel like it \& she also stopped asking me for I refused, besides she respect me 


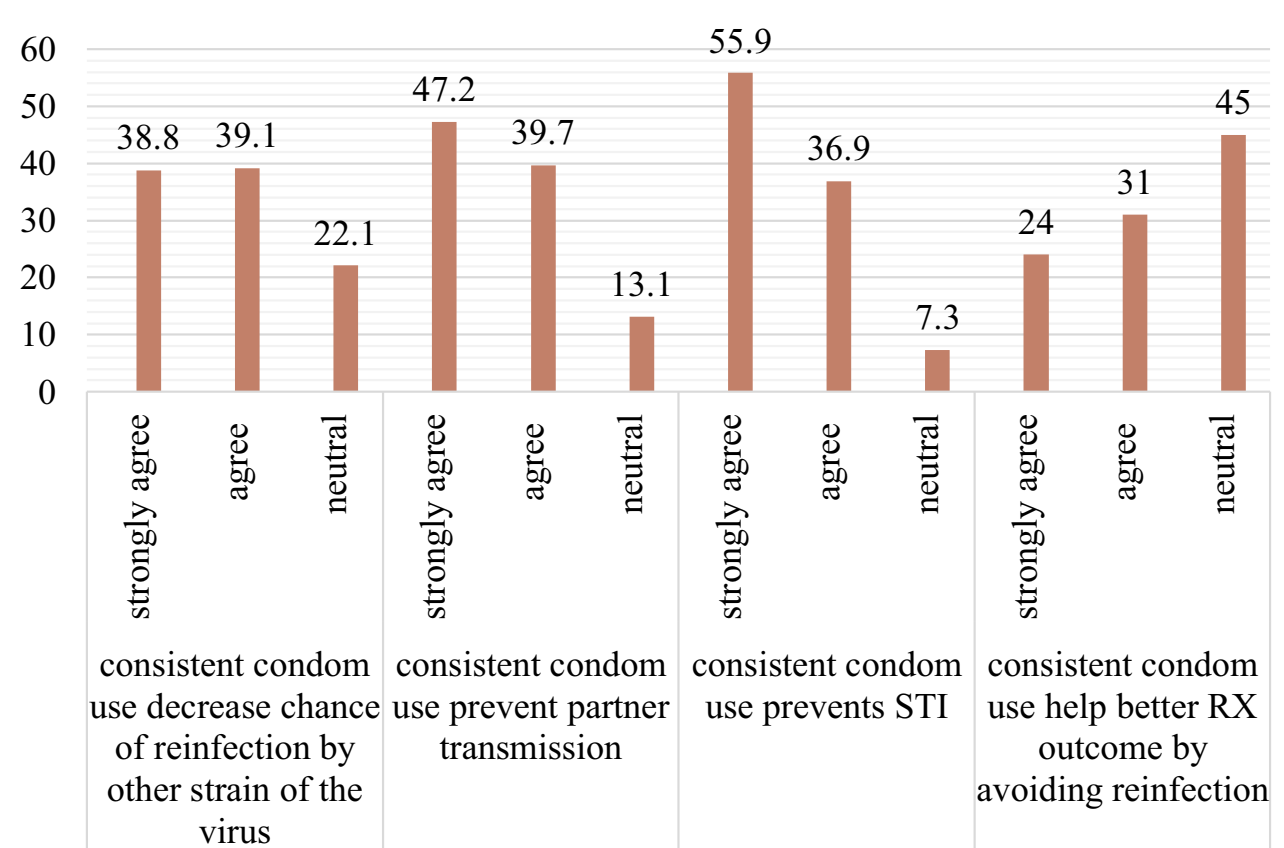

Figure 2 Distribution of factors related with perception on benefits of condom by PLWHA who are on ART in Hawassa city administration, 20I9 ( $\mathrm{n}=358$ ).

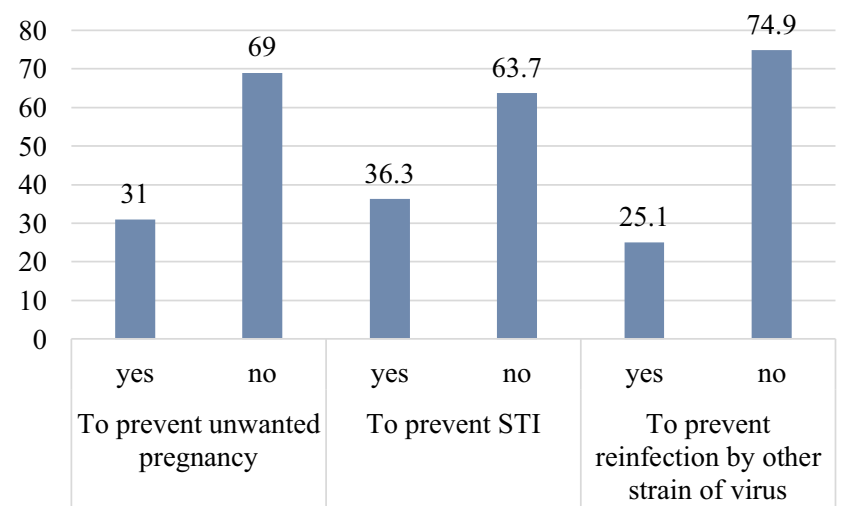

Figure 3 Reasons for consistent condom utilization by PLWHA who are on ART in Hawassa city administration, 2019.

... and $13(3.6 \%)$ reported religious reasons for not using a condom consistently (Figure 4) and all the key informants to complain that religious organizations are giving them a hard time to some extent. A key informant from the hospital said,

Clients say that they are told at religious places to throw away their drugs for they become negative upon religious rituals \& get lost for a long period of time discontinuing condom use as well, but when we find them, they are still positive \& affected with opportunistic infections except for one person who really tested negative. And others when entering to monastery \& nunnery they are told to leave their drugs at home for it is not allowed taking it with holy water \& they terminate their condom utilization practice upon their arrival back home.

Another informant from the same place said,

There are many terminating both condom \& ART proclaiming themselves as negatives for they have been told at religious \& holy water places of their freeness form the virus but they all tested positive except for one person who tested negative.

The informant from the health center said,

Nowadays the main reason for the negligence of condom use is a different schools of thought by different religious organizations. Our ART clients hear news proclaiming that they are free from HIV from religious organizations \& get lost for a long time discontinuing both the ART \& condom use. When we find these clients through our different tracking techniques, they are seen caught up with opportunistic diseases like TB with their CD4 count diminished from their pre discontinuation stage.

\section{Result from Thematic Content Analysis Key Informants Interview with Heath Care Workers} The key informants said there is difference in condom preference among clients in which there are some who like thinner (males) for the comfort it has. All the informants said that women are willing to use compared to men except for the sake of pregnancy. And all informants, when 


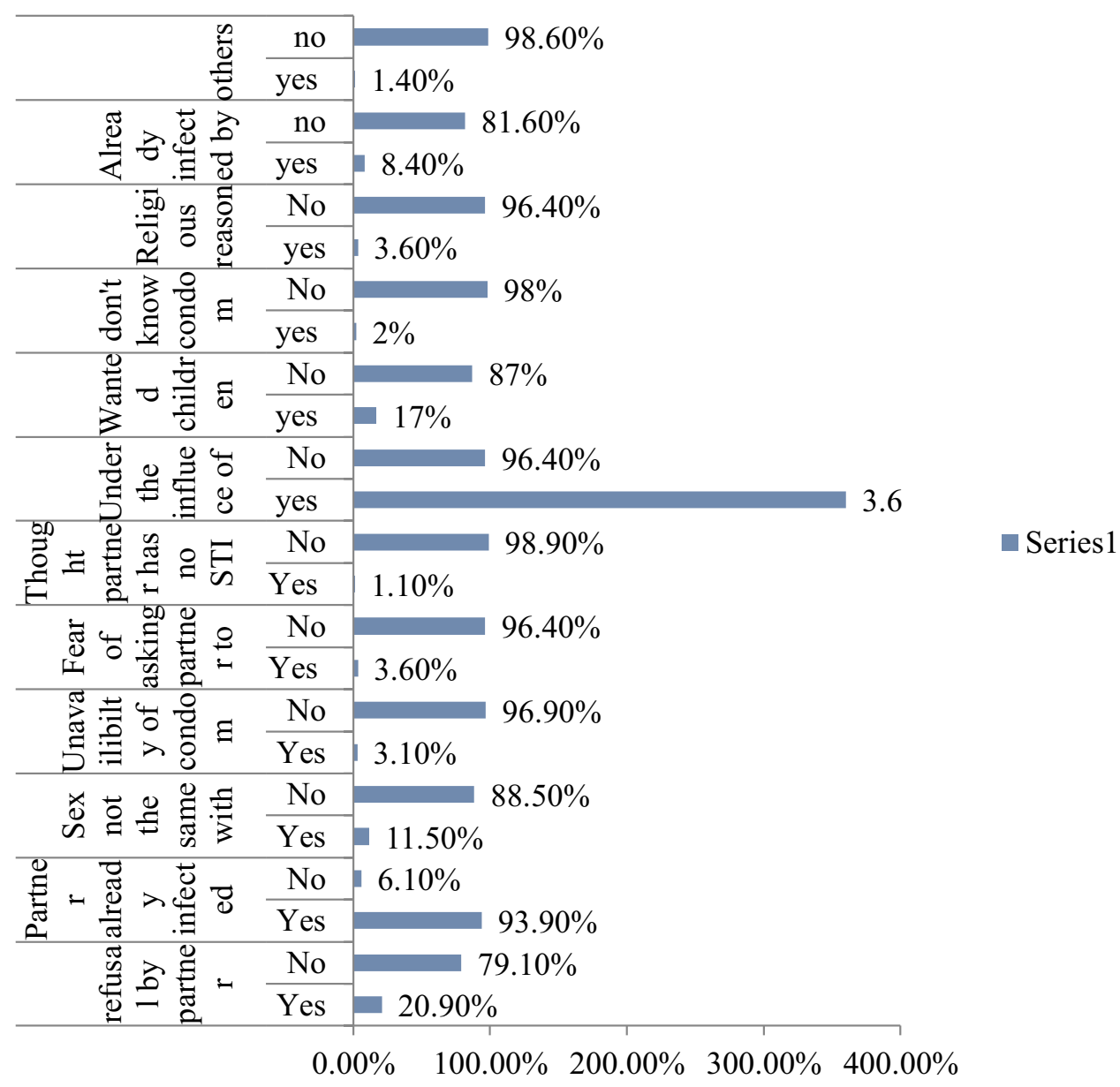

Figure 4 Reasons for non-consistent condom utilization by PLWHA who are on ART in Hawassa city administration, 2019 ( $\mathrm{n}=358$ ).

asked for the importance of condom, they mentioned prevention of STI, unwanted pregnancy, HIV \& prevention of re-infection by other strains among those who already are infected and they taught about the advantage of using condom for their clients.

All informants said there are clients who do not use condom consistently and their main reason for this is rejection by husbands, decrement in sexual satisfaction and religious reasons (clients on ART are told to stop condom utilization and even their medications at different religious organization after religious rituals). There also are some who think ART prevent HIV transmission and one informant said he came across with a discordant client who do not want condom because of love towards her husband.

\section{In-Depth Interview with PLWHA}

The most preferred condom by a female is the thicker one due to fear of burst but males prefer the thinner because they think the thicker decreases satisfaction. Half of the study participants had a discussion over safe sex and condom utilization. All the participants reported that ART has no negative effect on condom utilization. Around half of the participants did not use condoms consistently after ART \& the other half did use consistently while two participants have started using condoms due to obliging conditions after ART (uterine infection and pain upon urination).

Two third of the initiators of the idea of condom utilization during sex were females. All the participants know that consistent condom utilization prevents STI \& half reported it prevents transmission of HIV to others and re-infection by other strains and two-third of the respondent said that it prevents unwanted pregnancy.

Refusal by males and decrement in satisfaction were the main reasons for not using a condom consistently and one man who came from Oromia mentioned he wanted the beauty of his wife to fade because he had a fear that others would lust after her. Half of the response for the reason for consistent condom utilization was disallowance of sex without a condom by females, one husband said "she doesn't even trust me without making sure with her 
hands". Half of the response was for the sake of preventing transmission of other strains of the virus.

\section{Ever Given Birth and Future Desire of Children}

The finding in the table below shows that 268 (75\%) of the participants had ever given birth with $52.2 \%$ of the respondents reporting desire to have children in future (Figure 5).

\section{Counseling-Related Factors}

More than half 185 (51.7\%) of respondents reported not receiving follow-up counseling in the last three months and the opposite is true for the rest of them. The most common type of counseling received was about using a condom. Among those received follow-up counseling 55.2\% of them rated counseling on a condom by saying very good (Figure 6 ).

\section{Factors Associated with Consistent Condom Utilization}

After controlling for other variables, the odds of consistent condom utilization among females was found to be more than four times $(\mathrm{AOR}=4.20,95 \% \mathrm{CI}:(2.39,7.41))$ higher than that of males. Compared to those who reside in rural areas urban dwellers have more than three times $(\mathrm{AOR}=3.55,95 \%$ CI: $1.81,6.99)$ increased odds of consistent condom utilization. However, consistent condom utilization among those who have attended secondary education was less likely by $60 \%$ (AOR $=0.40,95 \%$ CI: $0.196,0.946)$ compared to those who have reported no education. The perception that ART does not reduce HIV transmission was associated with nearly two times (AOR $=1.96,95 \%$ CI: 1.12, 3.43) higher odds of consistent condom utilization compared to those who perceive the other way round. Those who rated the counseling

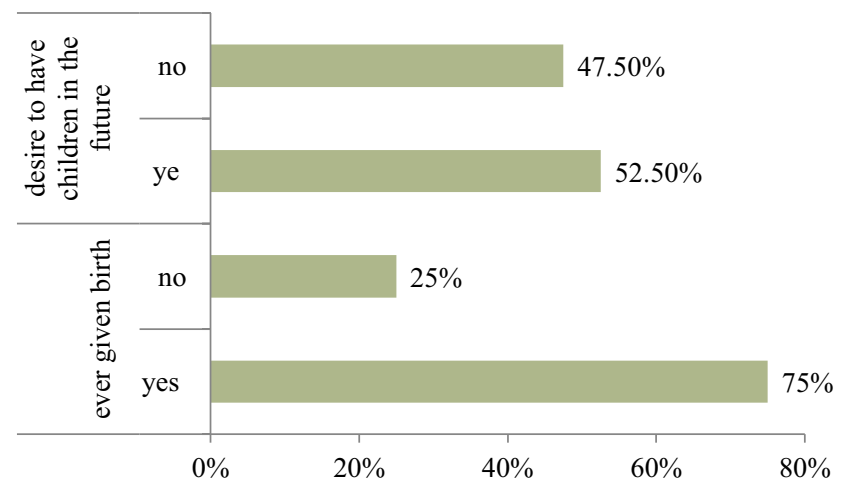

Figure 5 Distribution of ever given birth and future desire of children by PLWHA who are on ART in health institutions found in Hawassa city administration, 20I5/66 $(n=358)$.

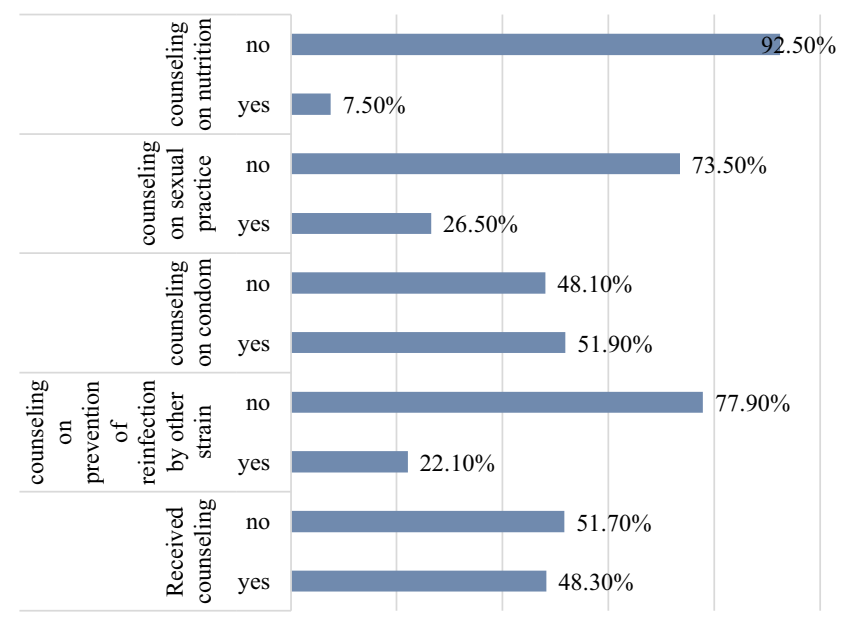

Figure 6 Distribution of counseling-related factors of PLWHA who are on ART in health institutions found in Hawassa city administration, $2019(n=172)$.

they received on a condom as Good have $63 \%$ fewer odds $(\mathrm{AOR}=0.37,95 \% \mathrm{CI}: 0.17,0.84)$ of consistent condom utilization compared to those who rated Very good. When it comes to reasons for consistent condom utilization, those who used for the sake of preventing unwanted pregnancy have more than four times ( $\mathrm{AOR}=4.52,95 \% \mathrm{CI}: 2.11,9.73$ ) increased odds of consistent condom utilization compared to those who do not use for the same reason (Table 5).

\section{Discussion}

The study assessed the magnitude of consistent condom utilization and associated factors among people living with HIV/AIDS who are on ART at health facilities found in Hawassa city and found the magnitude to be $51.4 \%$. Sex, educational status and perception towards ART's reduction of HIV transmission were found to be independent predictors of consistent condom utilization among ART users. Refusal by husbands, decrement in satisfaction, gender difference with more women than men willing to use consistently and religious reasons were factors associated with inconsistent condom utilization in the qualitative study.

The magnitude of consistent condom utilization found in this study is in line with the study in Gondar university hospital, North-Western Ethiopia, [50.2\%] (25), Hosanna $51.2 \%{ }^{37}$ and Nigeria $48.8 \% .{ }^{38}$ However, it is lower than studies conducted in different parts of Ethiopia, $63 \%$ in Addis Ababa, $71.0 \%$ in Fiche, $77.8 \%$ in Debrezeit, ${ }^{39-41}$ and $75.9 \%$ in Nigeria ${ }^{42}$ and in Hawassa $77.1 \%{ }^{43}$ This might be due to less implementation of counseling, the low desire of males in the current study but higher from other studies, and the difference in data collectors. 
Table 5 Multivariable Logistic Regression Analysis of Different Important Variables with Consistent Condom Utilization by PLWHA Who are on ART in Health Facilities Found in Hawassa City Administration, 2019. ( $n=358)$

\begin{tabular}{|c|c|c|c|c|c|}
\hline \multirow[t]{2}{*}{ Variables } & \multirow[t]{2}{*}{ Response } & \multicolumn{2}{|c|}{ Cons Con Utilization } & \multirow[t]{2}{*}{ COR $(95 \% \mathrm{Cl})$} & \multirow[t]{2}{*}{ AOR $(95 \% \mathrm{Cl})$} \\
\hline & & Yes & No & & \\
\hline \multirow[t]{2}{*}{ Sex } & Male & 55 (36.7\%) & 95 (63.3\%) & 1 & 1 \\
\hline & Female & $129(62.0 \%)$ & 79 (38.0\%) & $2.82(1.83,4.36)$ & $4.2 \mathrm{I}(2.39,7.4 \mathrm{I})^{* *}$ \\
\hline \multirow[t]{2}{*}{ Residence } & Urban & 159 (63.9\%) & $90(36.1)$ & $5.94(3.54-9.94)$ & $3.55(1.80,6.99)^{* *}$ \\
\hline & Rural & 25 (22.9\%) & $84(77.1)$ & I & I \\
\hline \multirow[t]{4}{*}{ Educational status } & No education & 33 (58.9\%) & $23(41.1 \%)$ & 1 & I \\
\hline & Primary & $7 \mid(53.8 \%)$ & 61 (46.2\%) & $0.8 I(0.43 I-I .528)$ & $0.89(0.39,2.09)$ \\
\hline & Secondary & 47 (4I.2\%) & $67(58.8 \%)$ & $0.49(0.26-0.94)$ & $0.40(0.17,0.95)^{*}$ \\
\hline & Above sec. & $33(58.9 \%)$ & $23(41.1 \%)$ & $1.00(0.47-2.12)$ & $1.43(0.53,3.83)$ \\
\hline \multirow[t]{2}{*}{ Perception that ART reduce HIV } & Yes & $64(38.8 \%)$ & $101(61.2 \%)$ & 1 & I \\
\hline & No & $120(62.2 \%)$ & $73(37.8 \%)$ & $2.59(1.69,3.98)$ & $1.96(1.12,3.43)^{*}$ \\
\hline \multicolumn{6}{|l|}{ Transmission } \\
\hline Rate of counseling & Good & 39 (50.6\%) & 38 (49.4\%) & $0.28(0.17,0.48)$ & $0.37(0.17,0.84)^{*}$ \\
\hline On condom & Very good & 68 (71.6\%) & $27(28.4 \%)$ & I & I \\
\hline Consistent & No & $92(37.2 \%)$ & $155(62.8 \%)$ & 1 & I \\
\hline Condom utilization to prevent unwanted pregnancy & Yes & $92(82.9 \% 0$ & $19(17.1)$ & $8.16(4.67-14.24)$ & $4.53(2.11,9.73)^{* *}$ \\
\hline
\end{tabular}

Notes: **Very highly significant, *Significant.

The finding of this study was higher than a study in North-Western Ethiopia, Felege Hiwot referral hospital $(44 \%) .{ }^{45}$ The difference could be ascribed to the time variation, in that the accessibility of information pertaining to condoms is now better than before and social desirability bias (as the data collectors were the ART providers).

This study found that consistent condom use is affected by sex. Females were 4.2 times more likely to use condom consistently than male. The study conducted in Kenya also showed that female ART clients were three times more likely to report inconsistent condom use compared to males. ${ }^{45}$ However, studies in different parts of Ethiopia like Gondar, Addis Ababa, Fiche, Debrezeit, and Northwest Ethiopia (Felege Hiwot hospital) and even in the study conducted in the same area (Hawassa) $)^{23,39-41,43,44}$ reported in contrary to the present study finding in which males are more likely for consistence condom utilization. This report is also supported by the qualitative finding in this study in which all the key informants said "except for the sake of pregnancy, females are very much willing to use condom consistently than males" and a husband interviewed from hospital supported this saying ... "She (wife) is more careful than me. She doesn't even trust me unless she makes sure with her hands" ... another respondent who is a commercial sex worker by profession said ... "It doesn't matter whether customers have a condom or not I always have mine with me. As I have learned a big lesson from here before I was put on ART" ... An unmarried man who indulged himself into casual sex said ... "every woman I met whether they are commercial sex workers or others, raise a question of using a condom"

The unusual female preponderance in consistent condom utilization might be due to the shift of male's need from a reduction of infection to seek satisfaction. This was supported by a qualitative finding that a man interviewed from Loke health center said ...."I used to use it sometimes but now after I'm put on HIV medications I stopped using it for it makes the satisfaction lesser" ...

Another man interviewed from the hospital responded saying ... "Though they have advised me about condoms when starting the medications, I never used it because I feared that it would lessen my satisfaction" ...

Respondents who have attended secondary education were $60 \%$ less likely to use condom consistently compared to those who have no education and this is in agreement with a study conducted at Lagos in Nigeria. ${ }^{38}$ However, study conducted in Italy and Nigeria showed that women with lower education reported inconsistent condom use more frequently. ${ }^{42,46}$ Another Ethiopian study conducted in Gondar also contradicts the present finding in which 
a higher level of educational status was observed to have a positive impact on the use of condoms consistently. ${ }^{44}$ The disagreement might be due to the conformity of lesseducated with counseling they have received from the ART clinic in the present study.

The odds of using condom consistently was 3.5 times higher among urban dwellers compared to rural dwellers. Similar finding was reported by the study conducted in Northwestern Ethiopia ${ }^{47}$ and another study in the same area, Felege Hiwot referral hospital showed a lower risk of practicing inconsistent condom use when being an urban resident. ${ }^{23}$ This could be explained by the information gap that would exist between these areas. Access to information, through media and various health institutions, may contribute to increased general awareness of and the importance of consistent condom use among people who are living in and around towns and cities and urban dwellers are highly exposed to health education from media and the availability of condoms in their vicinity.

This study revealed that respondents who perceived ART do not reduce HIV transmission had nearly two times higher odds of consistent condom utilization compared to those who perceive the others way round. This is in agreement with a study conducted in Hossana, Ethiopia. ${ }^{48}$ This might be due to a failure to recognize the benefits of ART among the users, because of weak counseling considering that counseling is a risk factor for this study.

This study showed that the odds of using condom consistently were $63 \%$ less among respondents who rated the counseling they received as good compared to those rated the counseling as very good. This might be due to the absence of language barriers this finding is also observed during the qualitative investigation that there was a disparity in the use of native language among providers and recipients of ART.

Respondents who use condom to prevent unwanted pregnancy have 4.5 times increased odds of consistent condom utilization compared to their counterparts. The main reasons for not using condom consistently mentioned were partners' refusal $(20.9 \%)$, sex is not same with the condom $(11.5 \%)$, participants mentioned unavailability of a condom (3.9\%), desire of fertility $(1.4 \%)$, already infected $(8.4 \%)$, feared asking partner to use a condom (3.6\%) and religious reasons $(3.6 \%)$. Among these main reasons the assumption that HIVinfected individuals do not need condoms since they are already infected, partner refusal, and desire to have children were in line with a study done in Mekella ${ }^{49}$ and Bahr Dar. ${ }^{23}$
Assumption that HIV-infected individuals do not need condoms since they are already infected is also in line with a study done in Gondar. ${ }^{50}$

Absence of discussion about a condom with partners, having multiple sexual partners, being negative serostatus partner and unknown partner serostatus are negatively associated with consistence condom utilization, ${ }^{39}$ alcohol use and non-disclosure ${ }^{38}$ are also negatively associated while membership in PLWHA association ${ }^{23}$ have a lower risk of practicing inconsistent condom use. Unlike all the above findings in different areas, the current study has no significant association with the variables mentioned needing further study of ascertainment with big sample size.

\section{Conclusion}

Nearly half of respondents engaged in non-consistent condom utilization, potentially resulting in re-infection by other strain of HIV viruses, other STDs \& onward transmission of the virus. In this study sex, residence, educational status, perception towards ART, rate of counseling and utilization of condom consistently to prevent unwanted pregnancy were variables demonstrated to be significantly associated with consistent condom utilization among PLWHA on the quantitative part. In light of this, increasing awareness about the importance of using condom can be a powerful means of fostering consistent condom use among patients receiving HIV drug treatment, in order to reduce the transmission. And on qualitative, gender difference with more women than male willing to use consistently, the difference in thickness of condom with seeking of satisfaction hampering consistency condom utilization, refusal by husband, the desire of pregnancy, decreased satisfaction when using a condom, religious reasons, where factors found to be associated with inconsistent condom use. There were a few limitations in this study. Social desirability bias might have occurred since data collectors were ART providers and non respondent from qualitative participant might have reduced variability of information which could have represented deviant cases. The importance of consistent condom use should be well addressed in HIV/ AIDS patients, to prevent transmission and multiple infections of HIV.

\section{Abbreviations}

AIDS, Acquired Immune Deficiency Syndrome; AOD, Adjusted odds ratio; ART, Anti-Retroviral Therapy; EDHS, Ethiopian Demographic Health Survey; ETB, Ethiopian Birr; 
Epi-Info, Epidemiological Information; HAART, Highly Active Antiretroviral Therapy; HIV, Human Immune Deficiency Virus; OR, Odds ratio; SPSS, Statistical Package for Social Science; SSA, Sub-saharan Africa.

\section{Data Sharing Statement}

"The dataset will not be shared in order to protect the participants' identities".

\section{Ethical Consideration}

Ethical clearance was obtained from the Institutional Review Board (IRB) of Public \& Environmental Health College of Hawassa University. An official letter of co-operation from the University had been written to Hawassa city health department. Before collecting the data, participants were told about the purpose, benefits and also assured of their right to refuse or withdraw from the study and such refusal or withdrawal would not affect their access to services related to ART. Discussions between data collectors and the respondents have taken place privately and individually. Participants' informed consent included publication of anonymized responses, and that this study was conducted in accordance with the Declaration of Helsinki.

\section{Acknowledgments}

The authors also recognize the invaluable funding, assured by all who contributed in the study, particularly the study participants and data collectors.

\section{Author Contributions}

BT planned the study, led and supervised the collected data and led analysis and drafted the manuscript and YS, BT and AE conceived the study, supervised and revised the MS, altogether authors read and accepted the final draft of the manuscript. All authors contributed to data analysis, drafting or revising the article, have agreed on the journal to which the article will be submitted, gave final approval of the version to be published, and agree to be accountable for all aspects of the work.

\section{Disclosure}

We the authors state that we do not have any conflicts of interest.

\section{References}

1. Organization WH, UNAIDS U. Global HIV/AIDS Response: Epidemic Update and Health Sector Progress Towards Universal Access: Progress Report 2017 [Internet]. Vol. 233. Geneva: WHO; 2017:2018.
2. HIV/AIDS JUNPo. Global Report: UNAIDS Report on the Global AIDS Epidemic 2013. Vol. 22. Geneva: UNAIDS; 2013:000-47.

3. Center for Communicable Disease ontrol. Condom Fact Sheet in Brief. Department of Health and Human Service. 2013.

4. United Nations Program for HIV/AIDS. Prevention Gap Report. 2016.

5. Akinyemi JO, Awolude OA, Adewole IF, Kanki PJ. Condom use among antiretroviral therapy patients in Ibadan, Nigeria. $J$ Infect Dev Ctries. 2010;4(08):495-502. doi:10.3855/jidc. 732

6. UNFPA, WHO, UNAIDS. Position Statement on Condoms and the Prevention of HIV, Other Sexually Transmitted Infections and Unintended Pregnancy. 2015. doi:10.1596/25763

7. Ali MS 1, Tesfaye Tegegne E 1, Kassa Tesemma M 2, Tesfaye Tegegne $\mathrm{K} 3$. Consistent condom use and associated factors among HIV-positive clients on antiretroviral therapy in North West Ethiopian health center, 2016 GC. AIDS Res Treat. 2019;2019:1-10. doi:10.1155/2019/7134908

8. Gitau M, Siyan YI. Determinants of inconsistent condom use among sero discordant couples in Cambodia. Am J Public HealthRes. 2016;4 (2):69-74.

9. Jiwatram-Negron T, El-Bassel N. Systematic review of couple-based HIV intervention and prevention studies: advantages, gaps, and future directions. AIDS and Behavior. 2014;18(10):1864-1887. doi:10.10 07/s10461-014-0827-7

10. Rodger A, Bruun T, Valentina C, et al. HIV transmission risk through condomless sex in HIV positive partners on suppressive antiretroviral therapy: PARTNER Study. CROI. 2014.

11. Federal Democratic Republic of Ethiopia. Country Progress Report on HIV/AIDS Response. Addis Ababa, Ethiopia; 2012.

12. Demographic E. Health Survey (2011) Addis Ababa. Ethiopia and Calverton, Maryland, USA: Central Statistical Agency and ICF International; 2012.

13. Health FMo. Ethiopian Strategic Plan for Intensifying Multi-Sectoral HIV/AIDS Response (2004-2008). Addis Ababa, Ethiopia; 2004.

14. UNAIDS. HIV/AIDS JUNPo. World AIDS Day Report 2011. Geneva, Switzerland; 2011.

15. Sarna A, Luchters S, Kaai S, Munyao P, Geibel S. Does being treated with HAART affect the sexual risk behavior of people living with HIV/AIDS? Insights from Mombasa Kenya. 2005.

16. Donnell DBJ, Baeten J, Kiarie J, et al. Heterosexual HIV-1 transmission after initiation of antiretroviral therapy: a prospective cohort analysis. Lancet. 2010;375(9731):2092-2098. doi:10.1016/S01406736(10)60705-2

17. Research RH eS. WHO. Reproductive Choices and Family Planning for People Living with HIV Counselling Tool. 2012.

18. Ayiga N. Rates and predictors of consistent condom-use by people living with HIV/AIDS on antiretroviral treatment in Uganda. J Health Popul Nutr. 2012;30(3):270-280. doi:10.3329/jhpn.v30i3.12290

19. Kennedy C, O'reilly K, Medley A, Sweat M. The impact of HIV treatment on risk behaviour in developing countries: a systematic review. AIDS Care. 2007;19(6):707-720. doi:10.1080/0954012070 1203261

20. Wamoyi JMM, Mbonye M, Seeley J, Birungi J, Jaffar S. Changes in sexual desires and behaviours of people living with HIV after initiation of ART: implications for HIV prevention and health promotion. BMC Public Health. 2011;11(1):633. doi:10.1186/1471-2458-11-633

21. Venkatesh KK, de Bruyn G, Lurie MN, et al. Decreased sexual risk behavior in the era of HAART among HIV-infected urban and rural South Africans attending primary care clinics. AIDS. 2010;24 (17):2687. doi:10.1097/QAD.0b013e32833e78d4

22. Shumba C, Atukunda R, Imakit R 1, Memiah P. Behavioral characteristics of adult patients on Highly Active Antiretroviral Therapy (HAART) in Uganda global. $J$ Med Public Health. 2012;1(1):32-37.

23. Yalew E, Zegeye DT, Meseret S. Patterns of condom use and associated factors among adult HIV positive clients in North Western Ethiopia: a comparative cross sectional study. BMC Public Health. 2012;12(1):1. doi:10.1186/1471-2458-12-308 
24. CSA I. Ethiopia Demographic and Health Survey 2011. Addis Ababa, Ethiopia and Calverton, Maryland, USA: Central Statistical Agency and ICF International; 2012.

25. Dave S, Stephenson J, Mercey D, Panahmand N, Jungmann E. Sexual behaviour, condom use, and disclosure of HIV status in HIV infected heterosexual individuals attending an inner London HIV clinic. Sex Transm Infect. 2009;82(2):117-119. doi:10.1136/sti.2005.015396

26. Man WYN, Kelly A, Worth H, Frankland A, Shih P, Martha KEA. Sexual risk behaviour, marriage and ART: a study of HIV-positive people in Papua New Guinea. AIDS Res Ther. 2013;10(17):1-12. doi:10.1186/1742-6405-10-17

27. Hassen MA. Assessment of sexual behavior, unmet reproductive health needs and fertility intention of people living with HIV/AIDS, Jimma, South West of Ethiopia. Glob J Med Res. 2013;13(2).

28. Ragnarsson A 1, Ekström AM 1, Carter J 1, et al. Sexual risk taking among patients on antiretroviral therapy in an urban informal settlement in Kenya: a cross-sectional survey. J Int AIDS Soc. 2011;14 (20):1-8. doi:10.1186/1758-2652-14-20

29. Lertpiriyasuwat C, Pradipasen M, Thiangtham W, Kaewduangjai P. Sexual behaviors during antiretroviral therapy among HIV-infected patients, Thailand. 2013.

30. Chakrapani V, Newman PA, Shunmugam M, Dubrow R. Prevalence and contexts of inconsistent condom use among heterosexual men and women living with HIV in India: implications for prevention. AIDS Patient Care STDS. 2012.

31. Browning MR, Evans MR, Rees CM. Continued high-risk sexual behaviour among HIV-positive people in Wales. Int J STD AIDS. 2009;14(11):737-739. doi:10.1258/09564620360719769

32. Benki-Nugent $\mathrm{S}$, Chung MH, Ackers $\mathrm{M}$, et al. Knowing a sexual partner is HIV-1-uninfected is associated with higher condom use among HIV-1-infected adults in Kenya. Sex Transm Dis. 2011;38 (9):808. doi:10.1097/OLQ.0b013e31821c3713

33. Stürmer M, Doerr HW, Berger A, Gute P. Case report is transmission of HIV-1 in non-viraemic serodiscordant couples possible? Antivir Ther. 2008;13:729-732.

34. Metsch LR, Pereyra M, Rio C, et al. Delivery of HIV prevention counseling by physicians at HIV medical care settings in 4 US Cities. Am J Public Health. 2004;94(7):1186-1192. doi:10.2105/AJPH.94.7.1186

35. Assefa N. Sexual behavior and determinants of condom use among HIV/AIDS patients who are on ART in North Shewa. East Afr J Public Health. 2013;10(4).

36. Makukula A. Impact of antiretroviral therapy on risky sexual behaviour of people living with HIV/AIDS on ART in Mansa. 2012.

37. Thanh DC, Hien NT, Tuan NA, Thang BD, Long NT, Fylkesnes K. HIV risk behaviours and determinants among people living with HIV/AIDS in Vietnam. AIDS Behav. 2012.
38. Ayoola OD, Victoria G-OC, Bamidele O, et al. Pattern, challenges and correlates of condom use among Nigerians living with HIV infection. Asian Pac $J$ Trop Biomed. 2014;4:S198-S203. doi:10.12980/APJTB.4.2014C1003

39. Demissie DB, Girma T, Abdissa G. Dual contraceptive utilization and associated factors among people living with HIV attending ART clinic in Fitche Hospital, Ethiopia. SM J Community Med. 2015.

40. Engedashet E, Worku A, Tesfaye G. Unprotected sexual practice and associated factors among people living with HIV at ante retroviral therapy clinics in Debrezeit Town, Ethiopia: a cross sectional study. BMC Public Health. 2014;11(1):56.

41. Adebayo AM, Ilesanmi OS, Omotoso BA. Disclosure to sexual partner and condom use among HIV positive clients attending ART clinic at a tertiary health facility in South West Nigeria. Pan Af Med J. 2014;18(245).

42. Walusaga HA, Kyohangirwe R, Wagner GJ. Gender differences in determinants of condom use among HIV clients in Uganda. AIDS Patient Care STDS. 2012;26(11):694-699. doi:10.1089/apc.2012.0208

43. Assefa E. Prevalence and factors associated with correct and consistent male condom use among people on antiretroviral treatment in Hawassa town, Ethiopia. J AIDS Clin Res. 2014;5:11.

44. Gelaw B, gelaw Y. Knowledge, attitude, practice and determinants of condom use among people living with HIV/AIDS in Gondar university hospital, North West Ethiopia. J Physiol Pharmacol Adv. 2013;3 (10):247-260. doi:10.5455/jppa.20130915065207

45. Bajunirwe F, Bangsberg DR, Sethi AK. Alcohol use and HIV serostatus of partner predict high-risk sexual behavior among patients receiving antiretroviral therapy in South Western Uganda. BMC Public Health. 2013;13(1):1. doi:10.1186/1471-2458-13-430

46. Cicconi P, d'Arminio Monforte A, Castagna A, et al. Inconsistent condom use among HIV-positive women in the "treatment as prevention era": data from the Italian DIDI study. J Int AIDS Soc. 2013;16 (1):18591. doi:10.7448/IAS.16.1.18591

47. Abadi Y, Kumar N. Assessment of consistent condom utilization and associated factors among ART attendees in mekelle Ethiopia. Int J Dev Res. 2015;5(01):3164-3172.

48. Tenaye K. Consistent condom use and associated factors among people living with HIV AIDS who are on ART in Hossana town, ETHIOPIA,2014. AAU; 2014.

49. Hurtado JJ, Pineda M, Cazali I, Mejía C. Knowledge of HIV transmission and condom use among HIV positive heterosexual men and women in (STIs). J Health Popul Nutr. 2011;14:58.

50. Sok P, Harwell JI, Dansereau L, et al. Pattern of sexual behavior of male patients before testing HIV positive in Cambodian hospital, Phnom Penh. Sex Health. 2011;5(4):353. doi:10.1071/SH08001
HIV/AIDS - Research and Palliative Care

\section{Publish your work in this journal}

HIV/AIDS - Research and Palliative Care is an international, peerreviewed open-access journal focusing on advances in research in HIV, its clinical progression and management options including antiviral treatment, palliative care and public healthcare policies to control viral spread. The manuscript management system is completely online and includes a very quick and fair peer-review system, which is all easy to use. Visit http://www.dovepress.com/testimonials.php to read real quotes from published authors. 